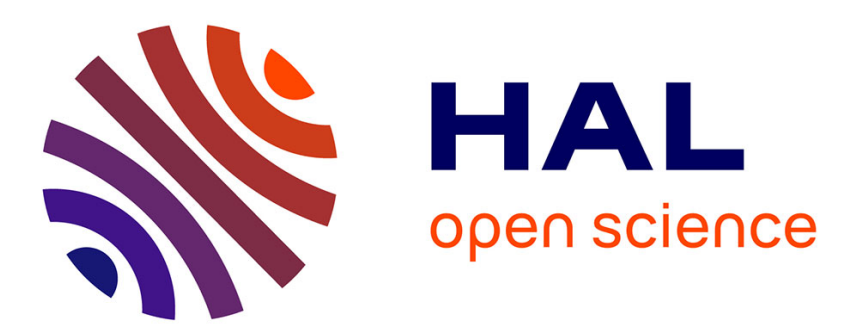

\title{
Modeling the mean interaction forces between powder particles. Application to silica gel-magnesium stearate mixtures.
}

Gérard Thomas, Yamina Ouabbas, Philippe Grosseau, Michel Baron, Alain

Chamayou, Laurence Galet

\section{To cite this version:}

Gérard Thomas, Yamina Ouabbas, Philippe Grosseau, Michel Baron, Alain Chamayou, et al.. Modeling the mean interaction forces between powder particles. Application to silica gel-magnesium stearate mixtures.. Applied Surface Science, 2009, 255 (17), pp.7500-7507. 10.1016/j.apsusc.2009.03.099 . hal-00409939

\section{HAL Id: hal-00409939 \\ https://hal.science/hal-00409939}

Submitted on 14 Aug 2009

HAL is a multi-disciplinary open access archive for the deposit and dissemination of scientific research documents, whether they are published or not. The documents may come from teaching and research institutions in France or abroad, or from public or private research centers.
L'archive ouverte pluridisciplinaire HAL, est destinée au dépôt et à la diffusion de documents scientifiques de niveau recherche, publiés ou non, émanant des établissements d'enseignement et de recherche français ou étrangers, des laboratoires publics ou privés. 


\section{MODELING THE MEAN INTERACTION FORCES BETWEEN POWDER \\ PARTICLES.}

\section{APPLICATION TO SILICA GEL-MAGNESIUM STEARATE MIXTURES.}

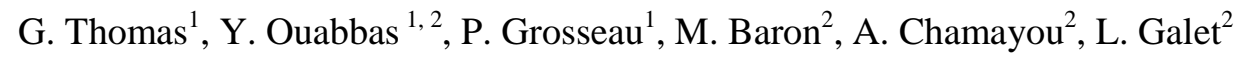

${ }^{1}$ Ecole Nationale Supérieure des Mines de Saint Etienne, Centre SPIN - LPMG -UMR CNRS 5148, 158 Cours Fauriel - 42023 Saint-Étienne Cedex, France

${ }^{2}$ Ecole Nationale Supérieure des Techniques Industrielles et des Mines d'Albi-Carmaux, Centre RAPSODEE - UMR CNRS 2392, Campus Jarlard - 81013 Albi, France

Corresponding author: Gerard Thomas, Ecole Nationale Supérieure des Mines de Saint-

Étienne, Centre SPIN, 158 cours Fauriel, 42023 Saint-Étienne cedex 02. Tel.+33 477420149. Fax.+33 4 77499692. E-mail: gthomas@emse.fr

\section{ABSTRACT}

Dry coating experiments were performed by using the Hybridizer (Nara). Large host silica gel (SG) particles $\left(\mathrm{d}_{50}=55 \mu \mathrm{m}\right)$ were coated with fine invited particles of magnesium stearate (MS, $\left.\mathrm{d}_{50}=4.6 \mu \mathrm{m}\right)$ for different contents of MS in the mixture. The real MS mass fraction $\mathrm{w}_{\mathrm{I}}$ obtained after mechanical treatment has been determined thanks to calibration from TGA measurements. The surface structure and morphology of MS coatings were observed using Environmental Scanning Electron Microscopy (ESEM) and Atomic Force Microscopy (AFM) $[26,27]$.

AFM has been also used to measure the adhesion forces between particles. Interaction forces between the material attached to the cantilever (Magnesium Stearate MS) and the surface of the composite material (Silica Gel SG or Magnesium Stearate MS) have been determined at different surface locations. For different compositions $\mathrm{w}_{\mathrm{I}}$ of the mixture MS-SG, the numeric distribution and the mean value $f$ of the forces $f_{H}$ obtained for MS-SG interactions or $f_{I}$ for MS-MS interactions have been established and the experimental curve showing the evolution of $\mathrm{f}$ versus $\mathrm{w}_{\mathrm{I}}$ has been derived. 
Models of ordered structures have been developed, implying morphological hypotheses concerning large spherical or cylindrical host particles $\mathrm{H}$ and small invited spherical $\mathrm{I}$. Different types of distribution of I materials onto the surface of $\mathrm{H}$ have been considered: for examples a discrete monolayer -or multilayers- of monosized particles I on the $\mathrm{H}$ surface. The coordinence of MS particles around SG particles has been estimated to calculate the free SG surface fraction through different modelling and to obtain the mean force $\mathrm{f}$ versus composition $\mathrm{w}_{\mathrm{I}}$. The theoretical force values have been compared to experimental ones. The deviations have been discussed in terms of guest particle distributions on the surface of the large host particles and morphological hypotheses.

PACS codes: $\quad$ 81.20.Ev: Powder processing

68.37. Ps: Atomic force microscopy (AFM)

81.70. Pg: Thermal analysis

Keywords: Powder mixtures, Dry coating, Hybridizer, Thermal analysis, AFM, Atomic interaction forces. 


\section{INTRODUCTION}

In a lot of industrial areas new applications or improvement of products functionalities require to modify the surface properties of powders. An interesting way to realize those modifications is the dry coating process. In such processes, powders with relatively large size (host particles: $1-500 \mu \mathrm{m})$ are mechanically coated with fine particles (invited particles: 0.1-50 $\mu \mathrm{m})$. Mechanical force applied to a mixture of fine and large particles can lead to ordered mixtures where guest particles are sufficiently small as to be held to the host surface by Van der Waals forces. The physical and physicochemical characteristics of the powders and the interactions between host and guest particles play an important role in factors that can affect the quality of end-product, as the physical and chemical stability and the powder ageing.

In this study the coating experiments have been carried out in the Hybridizer NSH0 [1 - 3], a lab-scale device supplied by the company Nara Machinery. This apparatus has been used for various purposes to carry out dry coating experiments. Its applications cover a large and diversified palette of areas including pharmaceutical industries [4 - 7] for taste masking or bio-availability enhancement, and composite materials area [8,9] for their mechanical or physical properties. It has been particularly described and studied by Honda and al [10 - 18], Dave and al. [19] Munjumbar [20] or more recently by Vilela and al. [21]. One of the important points that appeared in these works is the characterisation of the coated product in terms of quantity and quality of the coating.

This work is dedicated to the characterisation of dry coatings, and the study of interaction forces between invited and host particles by AFM force surface measurements. The ability to study particle-particle interactions is now possible with the advent of the atomic force microscope. Before measuring the interaction force as a function of tip-sample separation, the methodology used involves a critical step which consists in attaching the fine particles onto the AFM cantilever [22 - 24]. 


\section{PREPARING ORDERED MIXTURES OF PARTICLES}

\subsection{Powders}

Silica gel powder (SG) supplied by Merck has been used as host particles for dry coating experiments. This powder exhibits a porous structure characterized by a very hydrophilic behaviour. Its particles are irregularly shaped with a notable surface roughness (Figure 1). Magnesium Stearate (MS) supplied by Chimiray has been used as guest particles in order to use its hydrophobic properties for changing the Silica gel surface behaviour. The MS appears as a fine, white, greasy and cohesive powder widely used in pharmaceutical formulation as lubricant. Observations by ESEM (Figure 2) show a wide particle size distribution and shape including spheroids, needle and plate like particles.

Some physical properties of both powders are summarized in Table 1 . The size ratio, equal to 12, and the smallness of the MS size have been chosen to facilitate the adhesion of the guest particles on the host surface by means of Van der Walls forces.

Figure 1: ESEM picture of SG

Figure 2: ESEM picture of MS

Table 1. Some properties of the host and guest particles

\subsection{Coating process and operating parameters}

First, $30 \mathrm{~g}$ of mixtures of SG and MS have been prepared with different mass fraction $\mathrm{w}$ of MS. Then each premix has been introduced directly in the Hybridizer chamber (Figure 3). The rotor was activated at a speed of $4800 \mathrm{rpm}$ during $5 \mathrm{~min}$ and the products then recovered in the collector using an air purge. The rotation speed has been chosen in order to avoid too much grinding of the host particles but high enough to achieve a good circulation of the powder and a sufficient surface coverage yield in the collector.

During the coating process, host and guest particles are submitted to impacts between them, and with the rotor or the chamber walls (Figure 3). This treatment leads to the adhesion of the MS onto the SG surface. 
Figure 3: Scheme of the Hybridizer process

\subsection{ESEM observations}

The uncoated and coated Silica gel particles were examined by environmental scanning electron microscopy (ESEM) to study the surface morphology. The ESEM images revealed that greater MS coverage can be observed on the surface of SG particles as the MS mass ratio $w$ increased [25].

An example of coated particles observed with ESEM technique is presented in Figure 4. It let clearly appear the MS coating (dark zones) on the SG surface (white) in the case of an experiment carried out with $\mathrm{w}=15 \%$ before feeding the Hybridizer.

Figure 4: ESEM observation of SG particle coated with MS (w=15\%)

\subsection{Determination of the MS amount in the coated product}

After the hybridizer treatment, a part of the feed powder stayed stuck on the device walls. In particular, a significant deposit of MS in the Hybridizer was observed [26]. The real amount $\mathrm{w}_{\mathrm{I}}$ of MS in the SG-MS mixture has been quantified by using Differential Scanning Calorimetry coupled with Thermogravimetry (TG-DSC) in order to take into account a possible segregation of the particles and loss product during the process.

The analysis has been performed under nitrogen flow for a temperature ranging between 20$600{ }^{\circ} \mathrm{C}$ and heating rate of $5{ }^{\circ} \mathrm{Cmin}^{-1}$.

Figure 5: TG-DSC curves of SG sample

Figure 6: TG-DSC curves of MS sample

Figure 7: TG-DSC curves for $\mathrm{w}=15 \%$

The TG-DSC curves of SG (Figure 5) exhibited a water loss $\left(20^{\circ} \mathrm{C}-200^{\circ} \mathrm{C}\right)$ followed by a gradual surface hydroxyl groups departure. As seen in Figure 6, the MS decomposition occurs between about $250^{\circ} \mathrm{C}$ and $580^{\circ} \mathrm{C}$ after a dehydration step, corresponding to the loss of the structural water followed by the anhydrous MS decomposition in $\mathrm{CO}_{2}, \mathrm{CO}, \mathrm{H}_{2} \mathrm{O}$. As a consequence, for each SG-MS mixture, two mass losses can be observed (Figure 7). 
Figure 8: TG-DSC experimental relation between the mass lost $\left(\Delta \mathrm{m} / \mathrm{m}_{0}\right)$ and the introduced MS mass fraction (w)

Figure 9: Real MS mass fraction $\left(\mathrm{w}_{\mathrm{I}}\right)$ deduced from calibration curve versus the introduced MS mass fraction (w)

A calibration curve based (Figure 8) on well-known MS-SG mixtures prepared by simple stirring has been established by measuring the second mass loss $\left(\Delta \mathrm{m} / \mathrm{m}_{0}\right)$ [27]. The amount of remaining MS after Hybridizer dry coating experiments is deduced from the calibration curve by analysing the coated samples (Figure 9).

\subsection{Adhesion force measurements by AFM}

Atomic interaction forces between the MS attached to the cantilever [26, 27] and the surface of the composite material (SG or MS) have been determined at different locations of the surface. For different compositions $w$ of the mixture MS-GS, the numeric distributions (Figure 10) of the adhesion forces between MS attached to the AFM tip (spring constant, 0.32 $\mathrm{Nm}^{-1}$ ) and different samples have been established. The mean force ( $\mathrm{f}$ ), $\mathrm{f}_{\mathrm{H}}$ obtained for MSGS interactions or $f_{I}$ for MS-MS interactions have been determined and the experimental curve showing the evolution of $\mathrm{f}$ versus $\mathrm{w}_{\mathrm{I}}$ has been derived (Figure 11).

Figure 10: Numeric distributions of adhesion force between MS and the surface of each sample

Figure 11: Evolution of the mean adhesion force (f) versus the real MS mass ratio $\left(\mathrm{w}_{\mathrm{I}}\right)$ As observed in Figure 10 the adhesion forces for MS-MS interaction are in the range $40 \mathrm{nN}$ $150 \mathrm{nN}$ with a mean value $\mathrm{f}_{\mathrm{I}}$ of $68 \mathrm{nN}$ whereas $\mathrm{MS}-\mathrm{SG}$ adhesion forces are in the range $0 \mathrm{nN}$ $-20 \mathrm{nN}$ with a mean value $\mathrm{f}_{\mathrm{H}}$ of $8 \mathrm{nN}$.

In order to explain the evolution of the mean force $\mathrm{f}$ versus $\mathrm{w}_{\mathrm{I}}$, different models of perfectly ordered coatings or partially ordered structures are considered.

These models imply morphological hypotheses concerning large host particles $\mathrm{H}$ and small invited particles I in a mixture and different types of relative distribution of invited particles onto the surface of host ones. 


\section{MODELING ORDERED STRUCTURES OF PARTICLES}

The coordinence of small particles around host particles is estimated through different modelling and used to calculate the mean force $\mathrm{f}$.

\subsection{Hypotheses}

\section{a. Ordered structures are possible, which implies two conditions:}

The radius ratio $\mathrm{k}_{\mathrm{H}}$ of large host particles $\mathrm{R}_{\mathrm{H}}$ and that of small particles $\mathrm{R}_{\mathrm{I}}$ is large.

The sizes of $\mathrm{I}$ and $\mathrm{H}$ remain in the domain of strong microscopic interactions, but are not small enough to consider the occurrence of strong agglomerations of I or $\mathrm{H}$ particles.

\section{b. Morphology:}

The invited as well as the host particles are supposed to be spherical, and monosized. Nevertheless a discussion on the effect of cylindrical shape should be engaged to take into account in particular the real host morphology.

\section{c. Distribution of I on $\mathrm{H}$ :}

Two models are considered, a perfectly ordered structure of I around H (POC model), or a more random distribution of I over the host surface (SOC model).

In the first simple approach we consider a perfect discrete monolayer of monosized particles I on the $\mathrm{N}$ sites offered on the surface of the particle $\mathrm{H}$. So surface fractions $\mathrm{s}_{\mathrm{I}}$ and $\mathrm{s}_{\mathrm{H}}$ should be easily evaluated. This description would be the simplest most reasonable model in case of poor content of I in mixtures.

In fact this is a particular case of a more general distribution of particles I in several layers that will also be envisaged hereafter. In the second model, a host particle offers $\mathrm{N}$ surface sites to the invited particles added by the mechanical action of the mixer. Each layer of invited grains may contain $\mathrm{j}$ particles per host site $(\mathrm{j} €[0, \infty])$. After having installed $(\mathrm{p}-1)$ particles at random among the $\mathrm{N}$ sites, in mono, bilayers,... a snapshot locating a new particle I among the sites -occupied or not- will make the number of free sites vary. The number $\mathrm{q}_{\mathrm{p}}$ of 
free sites on the host after $\mathrm{p}$ snapshots is given by the equations $(1,2)$ where $\mathrm{N}$ is the initial number of free sites (after $\mathrm{p}=0$ snapshot), and $\mathrm{q}_{\mathrm{p}-1}$ the number of free sites on the surface after having placed at random p-1 particles. Starting from a situation where $\mathrm{q}_{\mathrm{p}-1}$ sites remain free after having injected $\mathrm{p}-1$ particles, when putting one more invited grain, the new value for the number of free sites will be the preceding one minus the probability $\left(\mathrm{q}_{\mathrm{p}-1} / \mathrm{N}\right)$ to place the new grain on a free site:

$$
\begin{aligned}
& \mathrm{q}_{\mathrm{p}}=\mathrm{q}_{\mathrm{p}-1}-\frac{\mathrm{q}_{\mathrm{p}-1}}{\mathrm{~N}} \\
& \mathrm{q}_{\mathrm{p}}=\mathrm{N}\left(1-\frac{1}{\mathrm{~N}}\right)^{\mathrm{p}}
\end{aligned}
$$

The free surface fraction $\mathrm{s}_{\mathrm{H}}$ can be deduced immediately in each case:

For perfectly ordered systems which can be obtained for mixtures where the quantity of I is rather small to avoid interstitial and agglomeration effects $\mathrm{s}_{\mathrm{H}}$ is given by:

$$
\mathrm{s}_{\mathrm{H}}=\left(1-\frac{\mathrm{p}}{\mathrm{N}}\right)
$$

For semi-ordered systems the model available for intermediate contents of $\mathrm{I}$ in the mixture gives:

$$
\mathrm{s}_{\mathrm{H}}=\left(1-\frac{1}{\mathrm{~N}}\right)^{\mathrm{p}}
$$

For small contents of I equations (3) and (4) yield the same results.

\section{d. Behaviour of I - H mixtures:}

It is assumed that the probability for a particle I placed on the tip of the cantilever to encounter a free surface site is proportional to the available free surface fraction. If the particles I are placed at random on the surface of host grains, for a pointer made of I material analysing all the surface of a host particle, the probability to reach I-I interactions forces $\mathrm{f}_{\mathrm{I}}$ or I-H interactions forces $f_{H}$ will be proportional to the corresponding area analysed. This hypothesis implies to neglect lateral interactions I-H or I-I with respect to axial interaction. 
Therefore on can write the equations (5) available for the SOC model, and anyway the relationship (6) always true for the two models:

$$
\begin{aligned}
& f=\left(\sum s_{I j}\right) f_{I}+s_{H} f_{H} \\
& f=\left(1-s_{H}\right) f_{I}+s_{H} f_{H}
\end{aligned}
$$

\subsection{Modeling the mean force of interaction}

Now we are ready for determining the mean force that can be observed between the material attached to the cantilever- for instance I- and the material in front of it on the piece of surface being analysed - either $\mathrm{H}$, either I-, as a function of the composition of the mixture (mass fraction).

\subsubsection{Evaluation of the sites number $N$ on host surface}

For a perfect ordered cell a host grain is surrounded completely by a monolayer of $\mathrm{N}$ particles I in a compact $2 \mathrm{D}$ arrangement on the surface of $\mathrm{H}$. The number $\mathrm{N}$ is equal to the maximum coordinence of a sphere $\mathrm{H}$ defined as the number of direct bonds established between a central particle $\mathrm{H}$ surrounded by I particles only. Suzuki et al., or Dodds [28, 29] have proposed a general solution to evaluate $\mathrm{N}$. But whenever the size ratio $\mathrm{k}_{\mathrm{H}}$ is greater than $5, \mathrm{~N}$ can be evaluated very simply as follows.

The approach consists in evaluating the area of the surface of contact between host and invited particles. By dividing this area available for deposing I particles by the effective area occupied by one particle I on the surface of contact the maximum coordinence is obtained, the effective area is the area of a grain I projected perpendicularly to the surface, divided by the packing fraction. For a $2 \mathrm{D}$ compact grain arrangement of $\mathrm{I}$ onto $\mathrm{H}$ particles, the packing fraction $\mathrm{C}_{2 \mathrm{D}}$ will be that of a hexagonal structure. When considering a spherical geometry for both types of grains, this gives a sphere of contacts whose radius is equal to $R_{H}+R_{I}$ :

$$
\mathrm{N}=\frac{4 \mathrm{C}_{2 \mathrm{D}}\left(\mathrm{R}_{\mathrm{H}}+\mathrm{R}_{\mathrm{I}}\right)^{2}}{\mathrm{R}_{\mathrm{I}}^{2}}
$$


This value can be expressed as a function of the size ratio $\mathrm{k}_{\mathrm{H}}$ :

$\mathrm{N}=4 \mathrm{C}_{2 \mathrm{D}}\left(\mathrm{k}_{\mathrm{H}}+1\right)^{2}$

For a compact hexagonal structure: $C_{2 D}=\frac{\pi}{2 \sqrt{3}}$ i.e. $C_{2 D}=0.906$, whereas for a random arrangement $C_{2 D}=\frac{\pi^{2}}{12}$ i.e. $C_{2 D}=0.82$, and for a quadratic loose packing $C_{2 D}=\frac{\pi}{4}$ i.e. $\mathrm{C}_{2 \mathrm{D}}=0.785$.

\subsubsection{Perfectly ordered structures}

For perfectly ordered monolayer systems, $s_{H}$ is given by equation (3) for a mixture in which $p$ particles I are mixed with one particle $\mathrm{H}$ so that the numerical fraction of I can be written

$\mathrm{n}_{\mathrm{I}}=\mathrm{p} /(1+\mathrm{p})$

The value of the number $\mathrm{p}$ of invited grains $\mathrm{I}$ on the surface of one host particle $\mathrm{H}$ as function of the radius ratio, the volumic mass and the mass fraction $\mathrm{w}_{\mathrm{I}}$ can be derived:

$$
\mathrm{p}=\mathrm{k}_{\mathrm{H}}{ }^{3} \frac{\rho_{\mathrm{H}}}{\rho_{\mathrm{I}}} \frac{\mathrm{w}_{\mathrm{I}}}{\left(1-\mathrm{w}_{\mathrm{I}}\right)}
$$

Then the expression (6) of the mean force becomes:

$$
\mathrm{f}=\left(\frac{\mathrm{p}}{\mathrm{N}}\right) \mathrm{f}_{\mathrm{I}}+\left(1-\frac{\mathrm{p}}{\mathrm{N}}\right) \mathrm{f}_{\mathrm{H}}
$$

Now one can express the mean force versus $\mathrm{w}_{\mathrm{I}}$ :

$$
\mathrm{f}=\left(\frac{\mathrm{k}_{\mathrm{H}}{ }^{3} \frac{\rho_{\mathrm{H}}}{\rho_{\mathrm{I}}} \frac{\mathrm{w}_{\mathrm{I}}}{\left(1-\mathrm{w}_{\mathrm{I}}\right)}}{4 \mathrm{C}_{2 \mathrm{D}}\left(\mathrm{k}_{\mathrm{H}}+1\right)^{2}}\right) \mathrm{f}_{\mathrm{I}}+\left(1-\frac{\left.\mathrm{k}_{\mathrm{H}}{ }^{3} \frac{\rho_{\mathrm{H}}}{\rho_{\mathrm{I}}} \frac{\mathrm{w}_{\mathrm{I}}}{4 \mathrm{C}_{2 \mathrm{D}}\left(\mathrm{k}_{\mathrm{H}}+1\right)^{2}}\right)}{\left.\mathrm{w}_{\mathrm{I}}\right)}\right) \mathrm{f}_{\mathrm{H}}
$$

$\mathrm{p}=\mathrm{N}$ corresponds to the maximum of the coverage for perfectly ordered systems when $\mathrm{p}$ reaches its maximum limit value. Therefore the limit mass fraction $\mathrm{w}_{\mathrm{LI}}$ can be written as a function of the size ratio:

$$
\mathrm{W}_{\mathrm{LI}}=\frac{1}{1+\frac{\rho_{\mathrm{H}}}{\rho_{\mathrm{I}} 4 \mathrm{C}_{2 \mathrm{D}}\left(\mathrm{k}_{\mathrm{H}}+1\right)^{2}} \mathrm{k}_{\mathrm{H}}{ }^{3}}
$$


When $w_{I} \geq w_{L I}$ then $f$ reaches the constant value $f_{I}$.

\subsubsection{Semi - ordered structures}

In this model, the systems are constituted of host particles $\mathrm{H}$ attracting at random small particles I.

For a multilayer distribution, one gets (15) from relation (4):

$\mathrm{p}$ (number of particles around a host in one or several layers) may be defined as a function of the mass fraction $\mathrm{w}_{\mathrm{I}}$ of I as given by (10):

So the expression of the free surface fraction becomes:

$\mathrm{S}_{\mathrm{H}}=\left(1-\frac{1}{4 \mathrm{C}_{2 \mathrm{D}}\left(\mathrm{k}_{\mathrm{H}}+1\right)^{2}}\right)^{\frac{\rho_{\mathrm{H}} k_{\mathrm{H}^{3} \mathrm{w}_{\mathrm{I}}}}{1-\mathrm{\rho}_{\mathrm{I}}}}$

$\mathrm{f}=\left(1-\left(1-\frac{1}{4 \mathrm{C}_{2 \mathrm{D}}\left(\mathrm{k}_{\mathrm{H}}+1\right)^{2}}\right)^{\frac{\rho_{\mathrm{H}_{\mathrm{H}}} k_{\mathrm{H}} \mathrm{p}_{\mathrm{I}}}{1-\mathrm{w}_{\mathrm{I}}}}\right) \mathrm{f}_{\mathrm{I}}+\left(1-\frac{1}{4 \mathrm{C}_{2 \mathrm{D}}\left(\mathrm{k}_{\mathrm{H}}+1\right)^{2}}\right)^{\frac{\rho_{\mathrm{H}} \mathrm{\rho}_{\mathrm{H}}{ }^{3} \mathrm{w}_{\mathrm{I}}}{1-\mathrm{w}_{\mathrm{I}}}} \mathrm{f}_{\mathrm{H}}$

For small $\mathrm{w}_{\mathrm{I}}$ this function exhibits almost the same variations as those given by the function (12), but some deviations can be noticed for $\mathrm{w}_{\mathrm{I}} \geq 5 \%$.

\section{COMPARAISON BETWEEN EXPERIMENTAL RESULTS AND MODELING - DISCUSSION}

The curves $\mathrm{f}\left(\mathrm{w}_{\mathrm{I}}\right)$ given by the models POC or SOC of Perfectly or Semi-Ordered Coatings have been compared to the experimental points (Figures 12 and 13).

The theoretical curves have been calculated after having attributed values to the following parameters: $\rho_{\mathrm{H}}=2.07 \mathrm{~g} \mathrm{~cm}^{-3}, \rho_{\mathrm{I}}=1.04 \mathrm{~g} \mathrm{~cm}^{-3}, \mathrm{k}_{\mathrm{H}}=12$.

For the POC model considering $\mathrm{H}$ and I spheres, the curves $\mathrm{f}\left(\mathrm{w}_{\mathrm{I}}\right)$ in Figure 12 corresponds to the cases $\mathrm{C}_{2 \mathrm{D}}=0.906$ (or $\mathrm{C}_{2 \mathrm{D}}=0.82$ ), from equation (12) with $\mathrm{N}=612$ (or $\mathrm{N}=554$ ) and $\mathrm{w}_{\mathrm{LI}} \sim 0.15$. The function exhibits an almost linear increase in the beginning as expected from 
equation (11) when $\mathrm{w}_{\mathrm{I}}<<1$, typically some percents. When $\mathrm{w}_{\mathrm{I}}>\mathrm{w}_{\mathrm{LI}}$ a plateau is reached at $\mathrm{w}_{\mathrm{LI}}=0.15($ or 0.14$)$

The curve (SOC model) on Figure 13 was obtained from equation (15) with two different values $\mathrm{C}_{2 \mathrm{D}}=0.906$ or 0.82 .

One can see that the experimental points are not in good agreement with the theoretical curve calculated with (12 or 15) with spheres (Figure 12) in the case of perfectly ordered coatings. A better agreement can be observed in the case of SOC models (Figure 13).

These deviations observed between experimental and theoretical curves $f\left(w_{I}\right)$ can be explained by different ways.

Figure 12: Perfectly Ordered Coating: evaluation of the averaged force of interaction between MS attached to the tip of the cantilever and the surface of spherical (or cylindrical) host particles covered by spherical invited particles MS, for different surface packing fractions.

Figure 13: Semi Ordered Coating: evaluation of the averaged force of interactions between MS attached to the tip of the cantilever and the surface of spherical (or cylindrical) host particles covered by spherical invited particles MS, for different surface packing fractions.

\section{MODELING DISCUSSION}

\subsection{Effect of the $2 \mathrm{D}$ packing of invited particles on the limit of saturation $\mathrm{w}_{\mathrm{LI}}$ can be evoked (POC models)}

A first study has been devoted to the effect of the choice of $\mathrm{C}_{2 \mathrm{D}}$ for perfect structures. Choosing $\mathrm{C}_{2 \mathrm{D}}=0.906$ gives the highest limit $\mathrm{w}_{\mathrm{LI}}$ at $15 \%$ and curves nearer to the experimental one whereas for $\mathrm{C}_{2 \mathrm{D}}=0.82, \mathrm{w}_{\mathrm{LI}}=14 \%$.

Going from a close compact surface structure to a random one i.e. decreasing $C_{2 D}=0.906$ to 0.82 will make $\mathrm{w}_{\mathrm{LI}}$ decrease by about $6 \%$. So the agreement between experimental and theoretical curves becomes better when choosing the highest value $C_{2 D}=0.906$.

\subsection{The role of the distribution of particles I over the host surface (SOC model)}

For less ordered systems, probably more real, with a random multi layers distribution of I on host (but always near the surface so that the system can be considered as partially ordered) the calculated curve $\mathrm{f}_{\mathrm{SOC}}\left(\mathrm{w}_{\mathrm{I}}\right)$ remains nearer the experimental curve than the corresponding curve 
$\mathrm{f}_{\mathrm{POC}}\left(\mathrm{w}_{\mathrm{I}}\right)$ for perfectly ordered systems, because the surface remains free in SOC systems, with more events of I-H type interaction forces.

In addition one may consider also that the I-I axial attraction force is much stronger $(68 \mathrm{nN})$ than the I-F axial attraction force $(8 \mathrm{nN})$ : this huge difference might orientate an I particle to be associated with another I particle on the host surface rather than to a free $\mathrm{H}$ site, less favourable from an energetic point of view, so that the postpone random distribution would become questionable.

\subsection{Effect of small lateral force interactions}

The hypothesis of small lateral force interactions between the material stuck on the tip and the surface on which interactions occur may also be discussed. This hypothesis implies to neglect lateral interactions I-H or I-H with respect to axial interaction. Effects due to an approach of the tip towards a locally non homogeneous surface (plan defects, local bad arrangements...) must lead to a larger distribution of $\mathrm{f}, \mathrm{f}_{\mathrm{I}}$ or $\mathrm{f}_{\mathrm{H}}$ measurements, which is noticed in the forces distributions curves presenting a very large standard deviation. This should lead to modify the basic equation (6).

\subsection{Effect of host particle morphology}

A model of ordered structures, implying morphological hypotheses like spherical large host particles $\mathrm{H}$ and small invited spherical particles has been developed. But models supposing spherical particles should be modified if the shape of particles is far from the sphere.

For instance the host particle seems to exhibit a shape not far from a cylindrical tablet. This real shape of host particles has been taken into account in new models POC-Cyl or SOC-Cyl. In this case $\mathrm{N}$ and $\mathrm{p}$ can be easily derived introducing the shape factors $\mathrm{k}_{\mathrm{cH}}=\mathrm{R}_{\mathrm{cH}} / \mathrm{R}_{\mathrm{I}}$ and $\mathrm{t}_{\mathrm{cH}}=$ $\mathrm{R}_{\mathrm{cH}} / \mathrm{e}_{\mathrm{H}}$ :

$\mathrm{N}=2 \mathrm{C}_{2 \mathrm{D}}\left[\mathrm{k}_{\mathrm{cH}}^{2}+\left(\mathrm{k}_{\mathrm{cH}}+1\right) \frac{\mathrm{k}_{\mathrm{cH}}}{\mathrm{t}_{\mathrm{cH}}}\right]$ 
$\mathrm{p}=\frac{3 \rho_{\mathrm{H}}}{4 \rho_{\mathrm{I}}} \frac{\mathrm{k}_{\mathrm{cH}}{ }^{3}}{\mathrm{t}_{\mathrm{cH}}} \frac{{ }^{\mathrm{w}_{\mathrm{I}}}}{\left(1-\mathrm{w}_{\mathrm{I}}\right)}$

(3) and (4) can be rewritten to get the general formula $f\left(w_{I}\right)$ analogous to equations (12) and (15).

To apply this new model one must pay attention to the fact that the host cylinder and the spherical one must present the same volume: this gives a relationship between the shape factors:

$\mathrm{k}_{\mathrm{cH}}=\mathrm{k}_{\mathrm{H}} \sqrt[3]{\frac{4 \mathrm{t}_{\mathrm{cH}}}{3}}$

To apply these models the shape factors have been determined by measuring on SG images the mean radius $\mathrm{R}_{\mathrm{cH}}$ and thickness $\mathrm{e}_{\mathrm{H}}$ of $\mathrm{SG}$ particles considered as tablets: we have obtained a ratio $\mathrm{t}_{\mathrm{cH}}=2$. From $(18)$ one can obtain $\mathrm{k}_{\mathrm{cH}}=19.6$.

By equalling $\mathrm{p}$ to $\mathrm{N}$ an equation giving $\mathrm{w}_{\mathrm{LI}}$ for the new POC-type model can be derived for cylindrical host particles:

$\frac{3 \rho_{\mathrm{H}}}{4 \rho_{\mathrm{I}}} \frac{\mathrm{k}_{\mathrm{cH}}{ }^{3}}{\mathrm{t}_{\mathrm{cH}}} \frac{{ }^{\mathrm{w}} \mathrm{LI}}{\left(1-\mathrm{w}_{\mathrm{LI}}\right)}=2 \mathrm{C}_{2 \mathrm{D}}\left[\mathrm{k}_{\mathrm{cH}}^{2}+\left(\mathrm{k}_{\mathrm{cH}}+1\right) \frac{\mathrm{k}_{\mathrm{cH}}}{\mathrm{t}_{\mathrm{cH}}}\right]$

This yields $\mathrm{N}=961$ with $\mathrm{C}_{2 \mathrm{D}}=0.82$ or $\mathrm{N}=1061$ for $\mathrm{C}_{2 \mathrm{D}}=0.906$ because the area of the surface offered to invited particles increases for the same mass of host particle. Anyway the limit does not move significantly: $\mathrm{w}_{\mathrm{LI}}=0.165$. The curve $\mathrm{f}\left(\mathrm{w}_{\mathrm{I}}\right)$ is just slightly shifted towards the experimental points.

In the same way this new SOC-type model with $\mathrm{C}_{2 \mathrm{D}}=0.906$ and cylinders as host particles yields the best agreement with experimental points.

\section{CONCLUSION}

Coating silica gel particles (SG) by small magnesium stearate particles (MS) has been realized, for different mass fraction $\mathrm{w}$ of MS with a treatment in a special mixer: the 
hybridizer "NARA. The real content $\mathrm{w}_{\mathrm{I}}$ in the mixture after treatment has been determined by TGA-DSC experiments. From AFM measurements, the interaction forces between from one hand MS material stuck on the tip of the cantilever, and from another hand of the surface of a silica gel particle, either free or occupied by MS particles have been obtained. From the adhesion force distribution curve, a mean value of the force has been derived.

Models to explain the evolution of this mean force versus the mass fraction have been proposed.

Considering a random distribution of invited particles on the surface of silica gel tablets and a cylinder like morphology for SG particles and spherical like for MS particles leads to the best agreement between the experimental and model results.

Nevertheless the deviations between theoretical curves and experimental ones could be also interpreted in terms of lateral interactions in MS-MS interaction forces.

The linear law $\mathrm{f}\left(\mathrm{s}_{\mathrm{H}}\right)$ introduced as the simplest approach of a mixing law as a function of a surface fraction could be considered as valid in a first approximation.

\section{ACKNOWLEDGEMENTS}

The authors would like acknowledge Anne-Marie Dana for the AFM interaction force measurements.

\section{REFERENCES}

[1]Yoshihara I., Pieper W., Hybridization - Technology for surface modification of powders without binders, Swiss Pharma, 21, 6, 1999

[2]Pfeffer R., Dave R. N., Dongguang W., Ramlakhan, M., Synthesis of engineered particulates with tailored properties using dry particle coating, Powder Technology, 117, 4067,2001

[3]Pieper W., The Nara hybridization design our own particle, Powder Handling and Processing, 8, 232-234, 1996

[4]Pieper W., Mattern C., Optimazation of taste masking pharmaceutical compounds by hybridization technique, Powder Handling and Processing, 16, 136-138, 2004

[5]Ishizaka T., Honda H., Kikuchi Y., Ono K., Katano T., Koishi M., Preparation drug diluent hybrid powder by dry processing, Journal of Pharmacy and Pharmacology, 41, 361- 
368,1989

[6] Ishizaka T., Honda H., Koishi M., Drug dissolution from indomethacin-starch hybrid powders prepared by dry impact blending method, Journal of Pharmacy and Pharmacology, 45, 770-774, 1993

[7] Ishizaka T., Kikuchi Y., Ono K., Hybridization of particles with reactive solid monomers by the dry impact blending method, Sixth International Symposium on Agglomeration, Japan, 1993

[8] Kangwantrakool S., Shinohara K., Sintering behaviour of mechanically coated Wc$\mathrm{Co} / \mathrm{TiC}-\mathrm{Al}_{2} \mathrm{O}_{3}$ particles by high-speed rotational impact blending, International Journal of Refractory and Hard Materials, 21, 171-182, 2003

[9] Feng C., Wang W., Fu Z., Fabrication of TiB2 composite powders coated with BN by high speed airflow impact, Trans. Nonferrous Met. Soc. China, 15, 2, 238-242, 2005

[10] Honda H., Ono K., Ishizaka T., Matsuno T., Katano M.

Surface modification of powders by the high speed impact treatment method, Journal of the Society of Powder Technology Japan, 24, 593-599, 1987

\section{[11] Honda H., Matsuno T., Koishi M.}

Preparation of a graphite fluoride modified-polymer microsphere by a high speed impact treatment method, Journal of the Society of Powder Technology Japan, 25, 597-602, 1988

\section{[12] Honda H., Matsuno T., Koishi M.}

The effect of powder properties on dry impact blending preparation method Journal of the Society of Powder Technology Japan, 25, 666-671, 1989

\section{[13] Honda H., Kimura M., Honda F., Matsuno T., Koishi M.}

Preparation of composite and encapsulated powder particles by dry impact blending International Journal of Chemistry and Biotechnology, 1991

\section{[14] Honda F., Honda H., Koishi M.}

Application of non-porous silica ultramicrospheres to high-performance liquid chromatographic column packings, Journal of Chromatography, 609, 49-59, 1992

\section{[15] Honda H., Kimura M., Honda F., Matsuno T., Koishi M.}

Preparation of monolayer particle coated powder by the dry impact blending process utilizing mechanochemical treatment, Colloids and Surfaces A: Physicochemical and Engineering Aspects, 82, 117-128, 1994

\section{[16] Honda F., Honda H., Koishi M.}

Utilization of the dry impact blending method to prepare irregularly shaped particles for highperformance liquid chromatographic column packings, Journal of Chromatography A, 696, 19-30, 1995

\section{[17] Honda F., Honda H., Koishi M., Matsuno T.}

Double-layered composite particles as a complex stationary phase for high-performance liquid chromatography, Journal of Chromatography A, 775, 13-27, 1997 
[18] Honda F., Honda H., Koishi M., Matsuno T.

Properties of cattle bone powder-coated composite particles as high-performance and open column liquid chromatographic column packings, journal of Chromatography A, 813, 21-33, 1998

[19] Dave R. N., Chen W., Mujumdar A., Wang W., Pfeffer R.

Numerical simulation of dry particle coating processes by discrete element method, Advanced Powder Technology, 14, 449-470, 2003

[20] Mujumdar A., Wei D., Dave R. N., Pfeffer R., Wu C. Y., Improvement of humidity resistance of magnesium powder using dry particle coating, Powder Technology, 140, 86-97, 2004

[21] Vilela A., Concepcion L., Accart P., Chamayou A., Baron M., Dodds J.A., Evaluation of the Mechanical Resistance of a Powder-powder Coating by Modulated Dry Feed Particle Size Analysis, Particle \& Particle Systems Characterization, Vol. 23, Issue 2, , pp127-132, 2006

[22] Butt H.J., Capella B., Kappl M., Force measurement with atomic force microscope: technique, interpretation and applications, Surface Science Reports, 59, 1-152, 2005

[23] Roberts C.J., What can we learn from atomic force microscopy adhesion measurements with single drug particles, European Journal of Pharmaceutical Sciences, 24, 153-157, 2005

[24] Eve J.K., Patel N., Luk S.Y., Ebbens S.J., Roberts C.J., A study of single drug particle adhesion interactions using atomic force microscopy, International Journal of Pharmaceutics, 238, 17-27, 2002

[25] Ouabbas Y., Chamayou A., Galet L., Baron M., Thomas G., Grosseau P., Guilhot B., (2008a), Surface modification of silica particles by dry-coating: Characterization and powder ageing, Powder Technology, in press.

[26] Ouabbas Y., Chamayou A., Galet L., Baron M., Dodds J., Danna A.M., Thomas G., Guilhot B., Grosseau P., Modification of powders properties by dry coating: some examples of process and products characteristics, submitted to Proceedings CHISA2008, Prague, august 2008

[27] Galet L., Ouabbas Y., Danna A.M., Thomas G., Grosseau P., Baron M., Chamayou A., Surface morphology analysis and AFM study of silica gel particles after mechanical dry coating with magnesium Stearate, submitted to Proceedings PSA2008, UK, September 2008

[28] Suzuki M., Oshima T., Estimation of the coordination number in a two-component mixture of cohesive spheres, Powder Tech., 36, 181-188, 1983

[29] Dodds J.A., The porosity and contact points in multicomponent random sphere packing calculated by a simple statistical geometric model, J. Coll. And Int. 77(2), 317-327, 1980

\section{Nomenclature}

$\mathbf{C}_{2 D}$ : packing fraction of the invited particles on the surface of contact I-H 
$\mathbf{e}_{\mathbf{H}}: \quad$ thickness of cylindrical host particles

f: mean force of interactions between Material $\mathrm{M}$ (attached on the cantilever) and the coated surface of a host particle

$\mathbf{f}_{\mathbf{I}}$ : mean force of interactions between Material $\mathrm{M}$ (on the cantilever) and the invited particles coating the surface of a host particle.

$\mathbf{f}_{\mathbf{H}}$ : mean force of interactions between Material $\mathrm{M}$ (on the cantilever) and the free surface of a host particle.

$\mathbf{k}_{\mathbf{H}}$ : $\quad$ size ratio of both spherical host and invited particles; $\mathrm{k}_{\mathrm{H}}=\mathrm{R}_{\mathrm{H}} / \mathrm{R}_{\mathrm{I}}$

$\mathbf{k}_{\mathbf{c H}}$ : $\quad$ size ratio for cylindrical host particle and spherical invited particles; $\mathrm{k}_{\mathrm{cH}}=\mathrm{R}_{\mathrm{cH}} / \mathrm{R}_{\mathrm{I}}$

$\mathbf{N}$ : initial number of free sites on host surface (after $\mathrm{p}=0$ snapshot), and also the maximum coordination number in an elementary cell composed of a particle $\mathrm{H}$ surrounded by small particles I only, forming a compact packing on the external surface of host particle $\mathrm{H}$.

$\mathbf{n}_{\mathbf{I}}$ : numerical fraction of I in the binary mixture $\mathrm{I}-\mathrm{H}$.

p: number of particles I placed at the surface among the $\mathrm{N}$ possible sites.

$\mathbf{q}_{\mathbf{p}}: \quad$ number of free sites on the surface after having placed at random $\mathrm{p}$ invited particles on a host particle

$\mathbf{R}_{\mathbf{I}}$ : $\quad$ radius of small spherical invited particles.

$\mathbf{R}_{\mathbf{H}}: \quad$ radius of large spherical host particles.

$\mathbf{R}_{\mathbf{c H}}$ : radius of large cylindrical host particles

$\mathbf{S}_{\mathrm{I} \mathbf{j}} \mathbf{S} \quad$ surface fraction of a layer containing $\mathrm{j}$ invited particles per host site on the surface of host grains presenting $\mathrm{N}$ sites.

$\mathbf{s}_{\mathbf{H}}: \quad$ free surface fraction on host particles; $\mathrm{s}_{\mathrm{H}}+\sum \mathrm{s}_{\mathrm{Ij}}=1$ and $\mathrm{s}_{\mathrm{H}}=\mathrm{q}_{\mathrm{p}} / \mathrm{N}$.

$\mathbf{t}_{\mathrm{cH}}: \quad$ shape factor of host cylinder particles; $\mathrm{t}_{\mathrm{cH}}=\mathrm{R}_{\mathrm{cH}} / \mathrm{e}_{\mathrm{H}}$

w: mass fraction of $\mathrm{I}$ in the $\mathrm{I}-\mathrm{H}$ mixture before the hybridizer treatment.

$\mathbf{w}_{\mathbf{I}}$ : mass fraction of $\mathrm{I}$ in the $\mathrm{I}-\mathrm{H}$ mixture after the hybridizer treatment.

$\mathbf{w}_{\mathbf{L I}}$ : limit mass fraction of $\mathrm{I}$ in the $\mathrm{I}-\mathrm{H}$ mixture corresponding to a complete coverage in perfect ordered coatings.

$\rho_{\mathrm{I}}, \rho_{\mathrm{H}}$ : volume mass of I and $\mathrm{H}$. 


\section{Figure Captions}

Figure 1: $\quad$ ESEM picture of SG

Figure 2: $\quad$ ESEM picture of MS

Figure 3: $\quad$ Scheme of the Hybridizer process

Figure 4: $\quad$ ESEM observation of SG particle coated with MS (w=15\%)

Figure 5: $\quad$ TG-DSC curves of SG sample

Figure 6: $\quad$ TG-DSC curves of MS sample

Figure 7: $\quad$ TG-DSC curves for $\mathrm{w}=15 \%$

Figure 8: TG-DSC experimental relation between the mass lost $\left(\Delta \mathrm{m} / \mathrm{m}_{0}\right)$ and the introduced MS mass fraction (w)

Figure 9: Real MS mass fraction $\left(\mathrm{w}_{\mathrm{I}}\right)$ deduced from calibration curve versus the introduced MS mass fraction (w)

Figure 10: Numeric distributions of adhesion force between MS and the surface of each sample

Figure 11: Evolution of the mean adhesion force (f) versus the real MS mass ratio ( $\left.\mathrm{W}_{\mathrm{I}}\right)$

Figure 12: Perfectly Ordered Coating: evaluation of the averaged force of interaction between MS attached to the tip of the cantilever and the surface of spherical (or cylindrical) host particles covered by spherical invited particles MS, for different surface packing fractions.

Figure 13: Semi Ordered Coating: evaluation of the averaged force of interactions between MS attached to the tip of the cantilever and the surface of spherical (or cylindrical) host particles covered by spherical invited particles MS, for different surface packing fractions. 


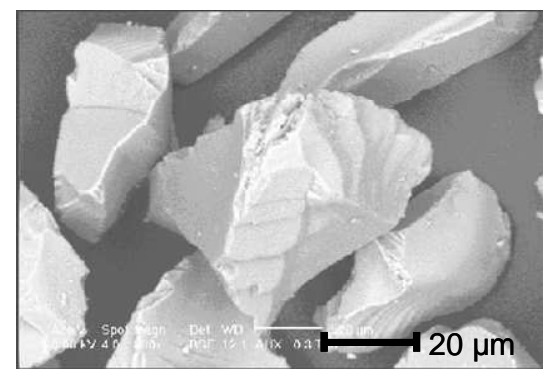

Figure 1

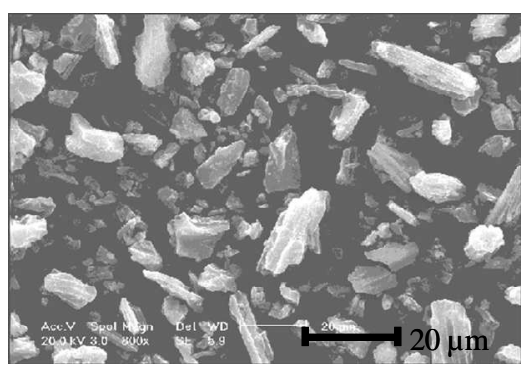

Figure 2

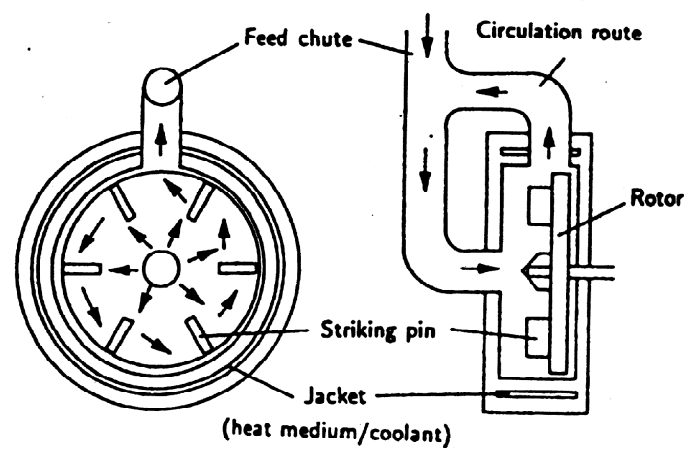

Figure 3
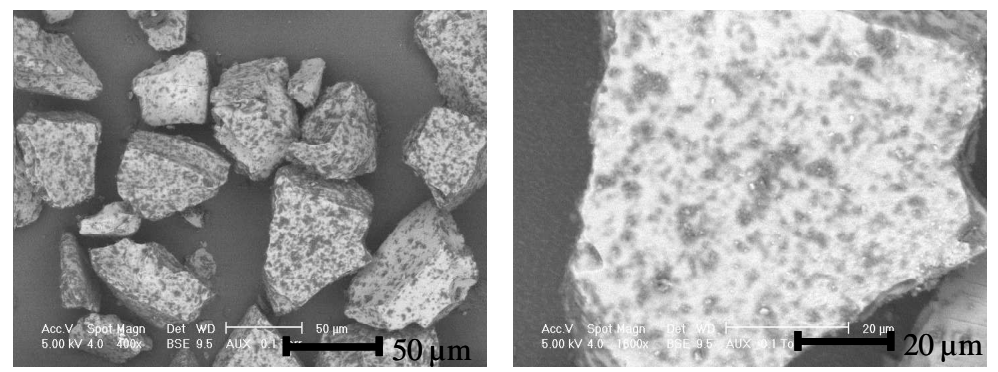

Figure 4 


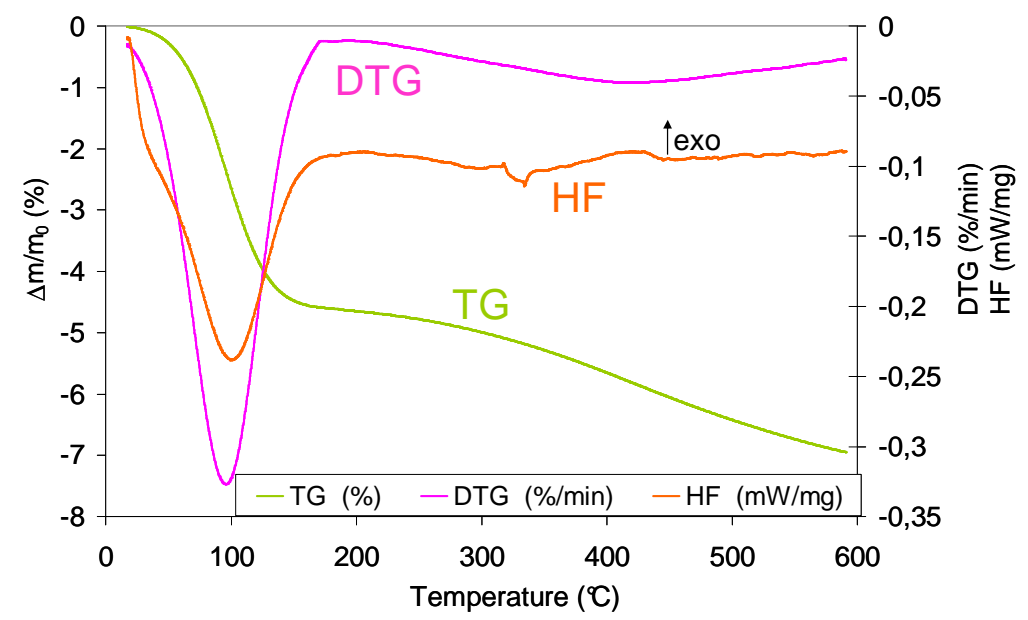

Figure 5

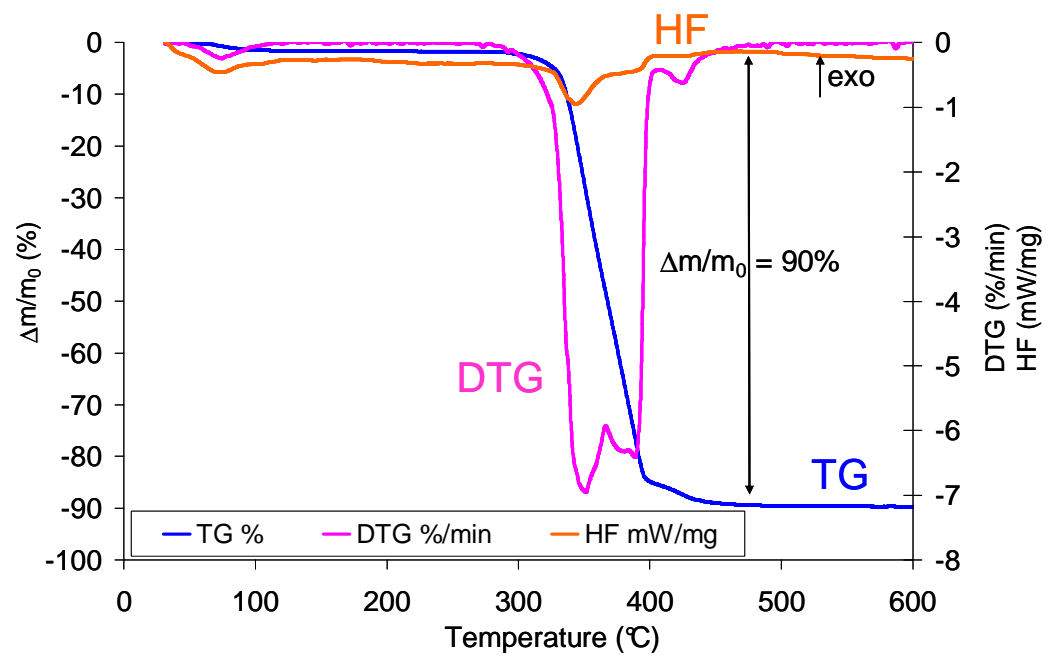

Figure 6

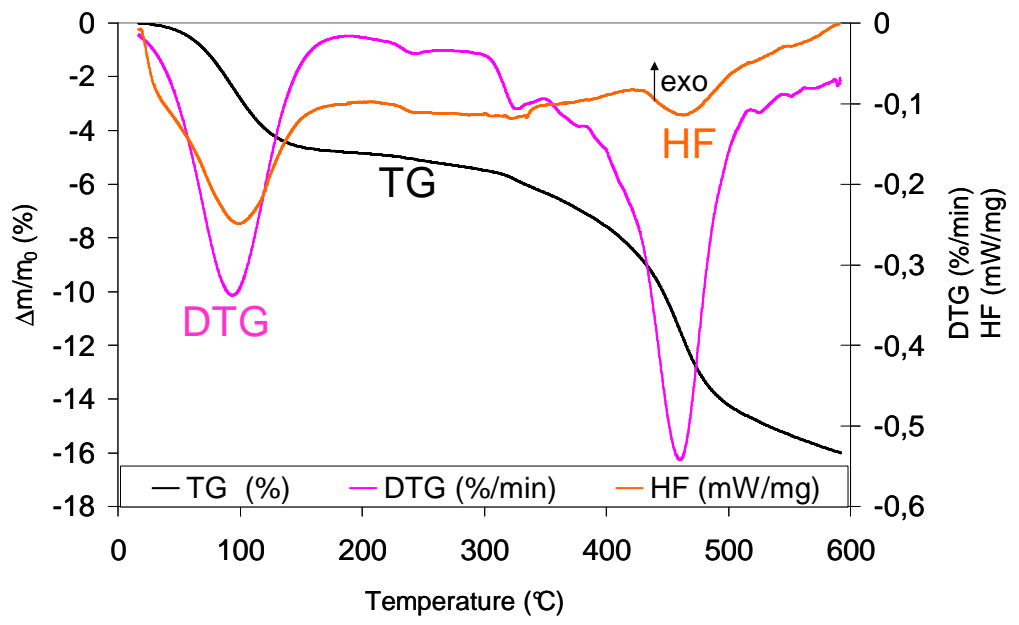

Figure 7 


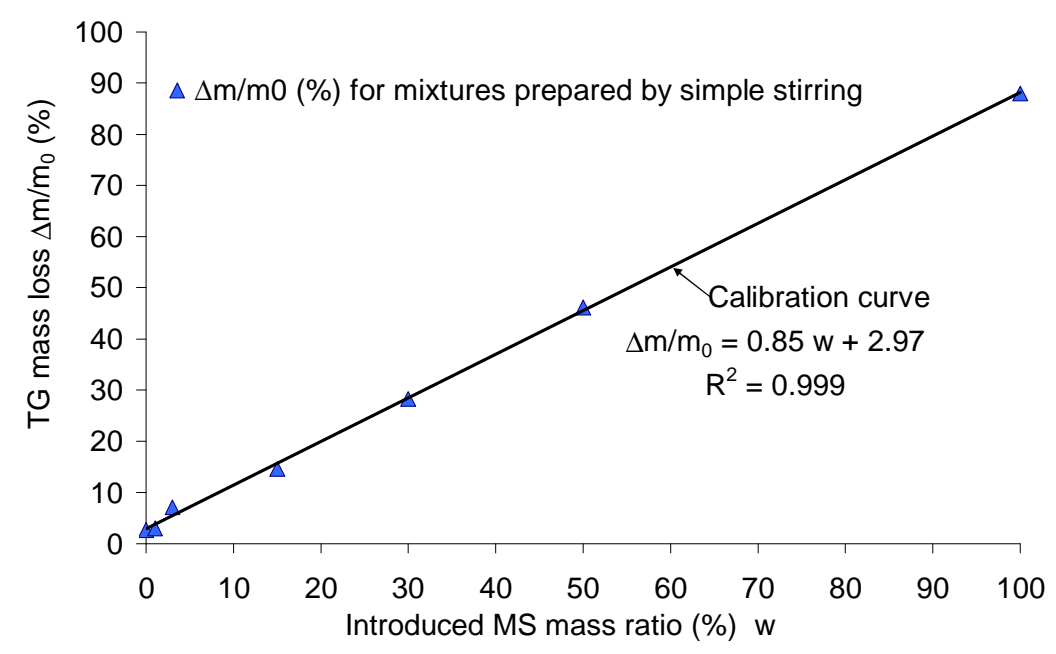

\section{Figure 8}

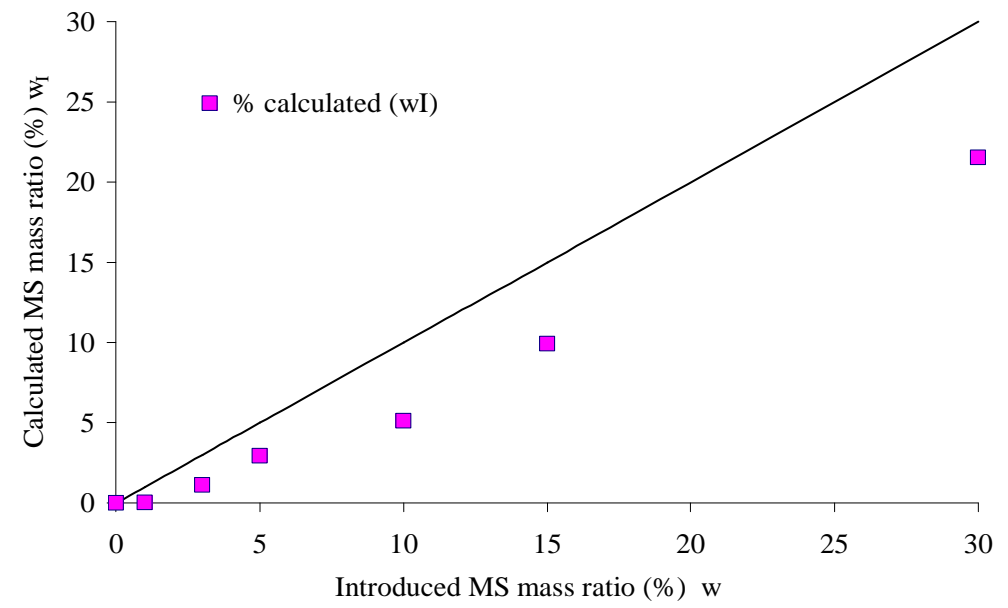

\section{Figure 9}

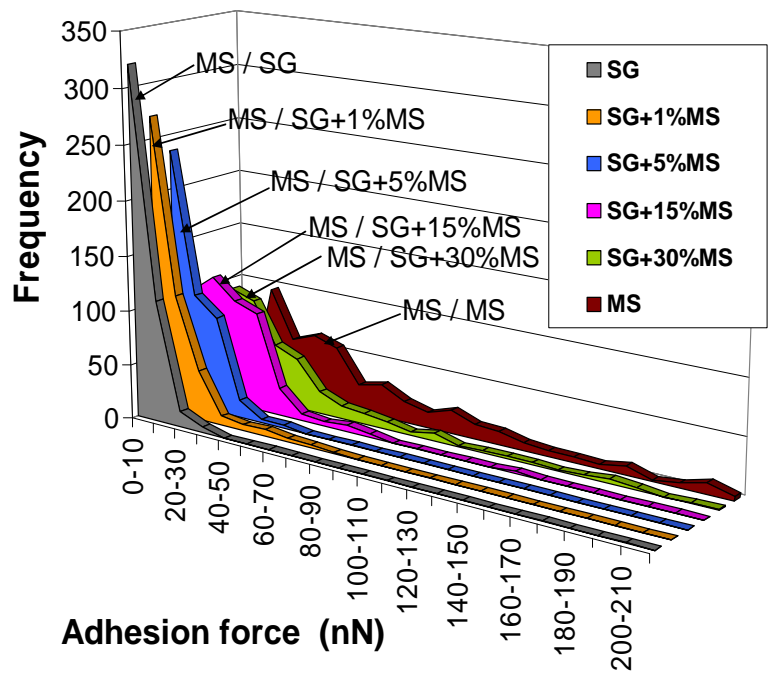

Figure 10 


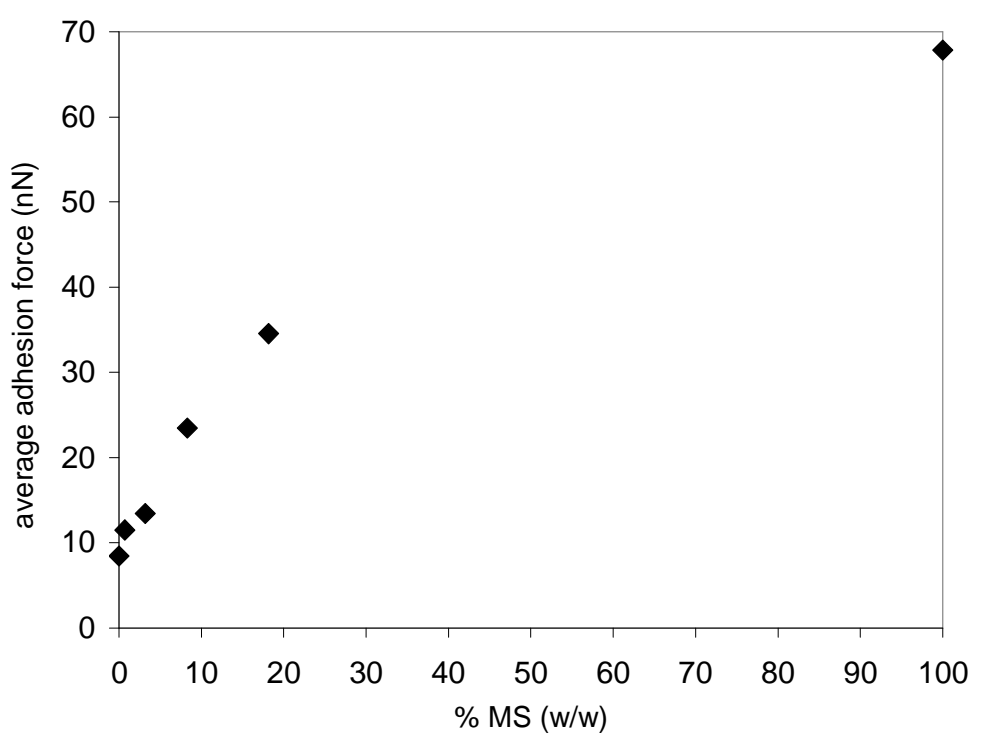

Figure 11

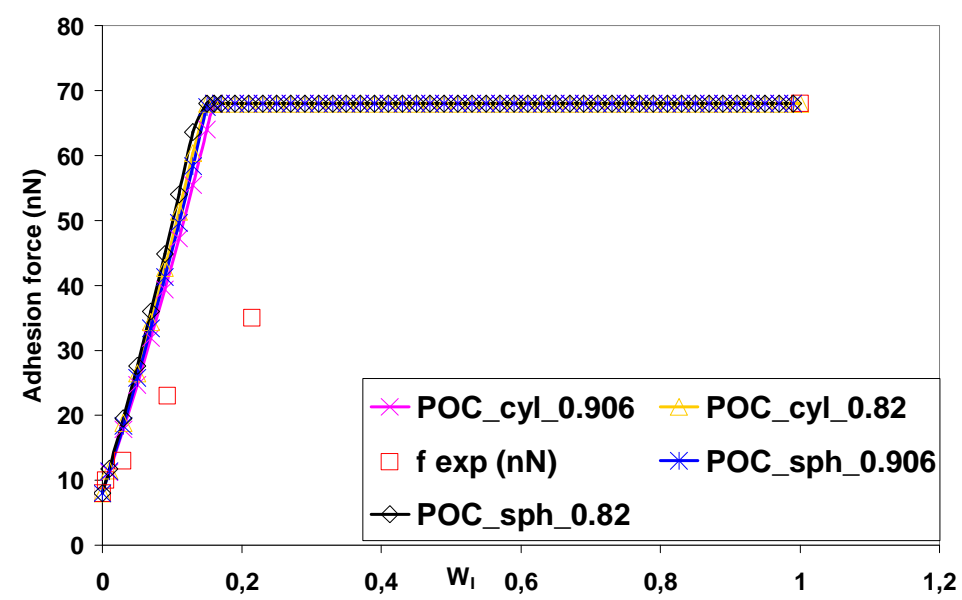

Figure 12

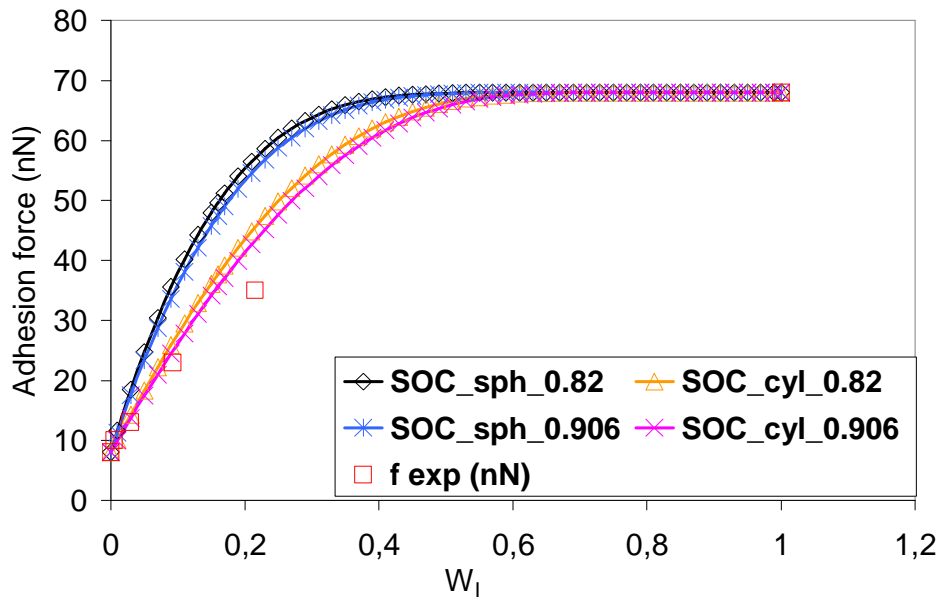

Figure 13 


\begin{tabular}{c|ccc}
\hline Particles & $\begin{array}{c}\text { Size }\left(\mathrm{d}_{50}\right) / \mu \mathrm{m} \\
\text { Mastersizer } \\
2000)\end{array}$ & $\begin{array}{c}\text { Density }(\rho) / \mathrm{g} \mathrm{cm}^{-3} \\
\text { (Helium Pycnometer: } \\
\text { Accupyc1330) }\end{array}$ & $\begin{array}{c}\text { Specific surface area }\left(\mathrm{S}_{\mathrm{BET}}\right) \\
/ \mathrm{m}^{2} \mathrm{~g}^{-1}\end{array}$ \\
\hline SG & $55\left(d_{H}\right)$ & $2.07\left(\rho_{H}\right)$ & 475 \\
\hline $\mathrm{MS}$ & $4.6\left(d_{I}\right)$ & $1.04\left(\rho_{I}\right)$ & 7.7 \\
\hline
\end{tabular}

Table 1. 